\title{
How the community pharmacist contributes to the multidisciplinary management of heart failure
}

\author{
E. Chauvelot ${ }^{1}$, V. Nerich ${ }^{1,2}$, S. Limat ${ }^{1,2}$, M. F. Seronde ${ }^{3}$, M. C. Woronoff-Lemsi ${ }^{1,2^{\star}}$ \\ ${ }^{1}$ Department of Pharmacy, University Hospital of Besançon, Besançon, France \\ ${ }^{2}$ School of Medicine and Pharmacy, Besançon, France; *Corresponding Author: marie-christine.woronoff-lemsi@univ-comte.fr \\ ${ }^{3}$ Department of Cardiology, University Hospital of Besançon, Besançon, France
}

Received 12 May 2010; revised 26 May 2010; accepted 3 June 2010.

\begin{abstract}
Objective: To define how the community pharmacist contributes to the management of heart failure by exploring the type of service he provides to patients and by assessing what patients expect from him. Setting: Pharmacists of the Franche-Comte region (France) and patients of the Franche-Comté Heart Association. Method: Two questionnaires were drawn up and sent to pharmacists and patients. Results: The 118 pharmacists participating in this survey $(36.9 \%)$ felt that they had a role to play in dispensing drugs $(100.0 \%)$, educating patients about their treatment $(83.1 \%)$, informing patients about the importance of observance $(81.4 \%)$ and overthe-counter drugs $(58.5 \%)$, distributing heart failure brochures $(51.7 \%)$ and providing medical equipment $(44.9 \%)$. On the other hand, only a third of them thought that they should inform patients about their illness and give advice by phone. On the whole, knowledge level is good for disease, drug therapy, contraindicated drugs, medical supervision and hygieno-dietetic management, but intermediate or poor for alert signs of decompensation, essential vaccinations and patient associations. University training in this area during formal pharmacy studies is considered either "insufficient" or "very insufficient" in $56.9 \%$ of cases. Although more than $99 \%$ of the pharmacists think that additional training is needed, only $33.1 \%$ had actually benefited from such training. Of the 96 patients $(48.0 \%)$ who completed the questionnaire, $92.6 \%$ are faithful to their pharmacist. They contact him more about drug therapy than about their disease, or information related to treatments. Roles attributed to their pharmacist are mainly related to drug therapy explanation and information con-
\end{abstract}

cerning over-the-counter drugs. Therapeutic education is known to $40.6 \%$ of interrogated patients. Among these patients, two-thirds depend on their pharmacist and feel that he is capable of providing the necessary education. Moreover, $46.2 \%$ of patients had received some form of therapeutic education from their pharmacist. Pharmacists believe that they are able to assume this role in $67.8 \%$ of cases. Conclusion: In spite of biases, this study allowed us to assess the expectations of heart failure patients with regard to the pharmaceutical management of their disease, thus clarifying the indispensable contribution that pharmacists make in the management of this disease.

Keywords: Heart Failure; Management; Community Pharmacist

\section{BACKGROUND}

Heart failure remains a common diagnosis and is an important public health problem [1]. The prevalence of heart failure exponentially increases with advanced age [2]. Depending on the severity of symptoms, heart dysfunction, age and other factors, heart failure can be associated with an annual morbidity and mortality of $5 \%$ to $50 \%$ [2]. Although many causes of heart failure exacerbations requiring hospitalisation can be identified, medication and dietary noncompliance have been reported as contributing factors in up to $33 \%$ of hospitalised patients [3]. However major advances in both diagnosis and management have occurred and will continue to improve symptoms and patient outcomes [4-6].

A multidisciplinary approach to managing patients suffering from heart failure has been shown to improve outcome [7]. Yet the place and the role of the community pharmacist in the multidisciplinary management of heart 
failure have not been defined. Pharmacists may play a role in drug dispensation, patient follow-up and monitoring of drug therapy. However, the role of the pharmacist could be extended.

Therefore, the aim of this study was to define how the community pharmacist contributes to the management of heart failure by exploring the type of service he provides to patients and by assessing what patients expect from him.

\section{METHOD}

\subsection{Study Design}

To achieve the aim of our study, we developed and sent two anonymous questionnaires, first to pharmacists and then to heart failure patients.

The first questionnaire, for pharmacists, was subdivided into five parts: 1/pharmacist characteristics: permanent (yes or no), how long he has had his qualifications $(<5,(5-9),(10-14),>15$ years $)$, pharmacy location (country, city center, urban district, shopping center), number of follow-up heart failure patients (0, (1-5), (6-10), (11-15), > 15), faithful patients (yes or no); 2/ knowledge of heart failure (disease, alert signs of decompensation, drug therapy, contraindicated drugs, hygieno-dietetic management, medical supervision, essential vaccinations, patient association) and role to play (in dispensing drugs, educating patients about their disease and treatment, informing patients about over-the-counter drugs and the importance of observance, referring patients to other health professionals or patient/support associations, providing medical equipment, giving advice by phone, distributing brochures about heart failure); 3/asked questions by patient: frequently (yes or no), ability to answer (frequently, sometimes, rarely, never), adopted behaviour if no answer (searching for answer in documents, on internet, contacting the patient's physician); 4/initial university training (very satisfactory, satisfactory, insufficient, very insufficient) and continuing education (necessary, yes or no); 5/therapeutic education: knowledge (yes or no), investment and motivation to provide it (yes or no), privacy space (yes or no).

This questionnaire was distributed to the pharmacists of the Franche-Comté region, via three wholesale distributors. One pharmacist per pharmacy was allowed to answer the questionnaire.

The second questionnaire, for patients, was subdivided into three parts: 1/patient characteristics: age (years), sex (female or male), duration of disease (years), residence (city or country), faithfulness to community pharmacist (yes or no) and grounds (good drug therapy knowledge or good advice provided by pharmacist; pharmacist listens attentively to patients and when necessary refers them to other health professionals; proximity of pharmacy, other); 2/roles and expectations regarding the way the pharmacist manages their disease: a) how often patients ask questions about disease or drug therapy (frequently, sometimes, rarely, never), pharmacists responses (very satisfactory, satisfactory, insufficient, very insufficient); b) good contact for any request related to disease or drug therapy, information on overthe-counter drugs, medical follow-up, medical supervision, hygienodietetic management, referral to other health professionals or support/patient associations (yes or no); 3/therapeutic education: knowledge (yes or no), trust pharmacist to provide it (yes or no), in pharmacy (yes or no).

This questionnaire with stamped envelope for return was distributed to patients of Association de Cardiologie de Franche-Comté (id est. Franche-Comté Heart Association).

Both questionnaires were accompanied by a letter explaining the aim of the study and instructions on how to return the completed questionnaire. Questionnaires were collected, centralized and analyzed.

\subsection{Statistical Analysis}

SAS 9.1® software was used for questionnaire analysis. Continuous variables were described by mean \pm standard deviation and median with ranges [minimum value maximum value] and qualitative variables by the number and percentage. Quantitative and qualitative variables were compared respectively by the Wilcoxon MannWhitney and the Fisher exact test or the chi square test. The tests were significant at an alpha threshold of $5 \%$ (p).

\section{RESULTS}

\subsection{Pharmacist Point of View}

\subsubsection{Pharmacist Characteristics}

Out of the 320 distributed questionnaires, 118 (36.9\%) were analysed. Results revealed that pharmacists are mainly permanent $(75.4 \%)$ and have been qualified for more than 15 years $(57.7 \%)$. Permanent pharmacists have been qualified longer than assistant pharmacists $\left(\mathrm{p}<10^{-4}\right)$. More than half of the pharmacists work in rural areas $(53.8 \%)$ and others in urban districts, city centers and shopping centers respectively in $23.1 \%$, $19.7 \%$ and $3.4 \%$ of cases. On the whole, they provide follow-up to more than ten heart failure patients $(70.1 \%)$. Heart failure patients tend to be very faithful $(96.6 \%)$. 


\subsubsection{Knowledge of Heart Failure and Role to Play} Pharmacists' assessment of their own knowledge of heart failure is summarized in Table $\mathbf{1}$.

Their knowledge level with regard to drug therapy, hygieno-dietetics, and essential vaccinations was significantly related to the number of patient follow-ups in the pharmacy (respectively, $\mathrm{p}=0.04, \mathrm{p}=0.01$ and $\mathrm{p}=$ $0.02)$. Pharmacists' knowledge level increased with the number of patients. Disease knowledge was significantly positively related to drug therapy knowledge $\left(\mathrm{p}<10^{-3}\right)$, contraindicated drugs and alert signs of decompensation knowledge $(\mathrm{p}=0.01)$.

Without taking into account drug dispensation $(100.0 \%)$, the pharmacist plays different roles in: educating patients about their treatment $(83.1 \%)$, informing them about the importance of observance $(81.4 \%)$ and over-the-counter drugs $(58.5 \%)$, distributing brochures about heart failure $(51.7 \%)$ and providing medical equipment (44.9\%).

One-third of the pharmacists in our study also play a role in educating patients about their disease $(35.6 \%)$ and providing advice by phone (33.0\%). Referral to other health professionals and support/patient associations was only found for respectively $22.0 \%$ and $11.0 \%$ of pharmacists.

\subsubsection{Questions Asked by Patients}

Pharmacists estimated that more than a third of all patients $(33.9 \%)$ often ask them questions. However, pharmacists were unable to answer these questions in $69.1 \%$ of cases. There is no significant difference between the frequency of questions and the ability to an

Table 1. Pharmacist self-evaluation: Knowledge of heart failure.

\begin{tabular}{lcccc}
\hline \multirow{4}{*}{$\mathrm{n}=118$} & \multicolumn{4}{c}{ Knowledge Level, number (\%) } \\
\cline { 2 - 5 } & $\begin{array}{c}\text { Very } \\
\text { Good }\end{array}$ & Good & Average & Poor \\
\hline $\begin{array}{l}\text { Disease } \\
\text { Alert signs of } \\
\text { decompensation }\end{array}$ & $6(3.4)$ & $68(57.6)$ & $43(36.4)$ & $3(2.5)$ \\
$\begin{array}{l}\text { Drug therapy } \\
\text { Contraindicated } \\
\text { drugs }\end{array}$ & $11(9.3)$ & $88(74.6)$ & $18(15.3)$ & $1(0.9)$ \\
$\begin{array}{l}\text { Medical } \\
\text { supervision }\end{array}$ & $11(9.3)$ & $59(50.0)$ & $42(35.6)$ & $6(5.1)$ \\
$\begin{array}{l}\text { Essential } \\
\text { vaccinations }\end{array}$ & $3(2.5)$ & $34(28.8)$ & $48(40.7)$ & $33(28.0)$ \\
$\begin{array}{l}\text { Hygieno-dietetic } \\
\text { management }\end{array}$ & $15(12.7)$ & $70(59.3)$ & $31(26.3)$ & $2(1.7)$ \\
$\begin{array}{l}\text { Patient } \\
\text { association }\end{array}$ & $0(0.0)$ & $3(2.5)$ & $29(24.6)$ & $86(72.9)$ \\
\hline
\end{tabular}

swer $(p=0.69)$. If the pharmacist cannot answer, immediately, he tries to find the answer in documents $(82.8 \%)$, on internet $(43.1 \%)$ or by contacting the patient's physician directly (68.1\%).

\subsubsection{Initial University Training and Continuing Education}

Initial university training about heart failure was judged satisfactory to very satisfactory by $43.1 \%$ of pharmacists. More than $99 \%$ of them consider it necessary to have a additional training. However, only $33.1 \%$ of pharmacists ever actually had continuing education. The older the qualifications, the more dissatisfied the pharmacist was with his initial university training $(\mathrm{p}=0.02)$ and the more interested he was in additional training $\left(\mathrm{p}<10^{-3}\right)$. Continuing education was also significantly positively related to the number of heart failure patient follow-ups in the pharmacy $(\mathrm{p}=0.04)$, permanent pharmacist status $(p=0.04)$, and how long the pharmacists has been qualified $\left(\mathrm{p}<10^{-3}\right)$.

\subsubsection{Therapeutic Education}

$77.1 \%$ of pharmacists participating in our study known about therapeutic education and they think that they are able to play this role in $67.8 \%$ of cases. More than two-thirds $(70.3 \%)$ have privacy space.

\subsection{Heart Failure Patient Point of View}

\subsubsection{Patient Characteristics}

Of the 200 questionnaires distributed to patients, 96 $(48.0 \%)$ were collected and analysed. Patient characteristics are summarized in Table 2. The mean age of disease was estimated at $8.3 \pm 0.9$ years, with a median of 6 years (1-51).

Patients are faithful to their pharmacist in $92.6 \%$ of cases for different grounds (Table 3). Patients living in the city are significantly more faithful than patients living in the country $\left(\mathrm{p}<10^{-2}\right)$. Listening and referral to other health professionals are significantly related to the sex of patients $(p=0.02)$ : these roles are important for

Table 2. Heart failure patient characteristics.

\begin{tabular}{lr}
\hline $\mathrm{n}=96$ & number (\%) \\
\hline Sex & $31(32.3)$ \\
$\quad$ Female & $65(67.7)$ \\
$\quad$ Male & \\
Age classes (years) & $12(12.5)$ \\
$\quad<60$ & $64(66.7)$ \\
$\quad(60-75)$ & $20(20.8)$ \\
$\quad>75$ & \\
Residence* & \\
$\quad$ City & $60(63.2)$ \\
Country & $35(36.8)$ \\
Faithfulness to the pharmacy* & \\
$\quad$ Yes & $88(92.6)$ \\
No & $7(7.4)$ \\
\hline
\end{tabular}


$32.0 \%$ of male patients as opposed to only $9.8 \%$ of female patients.

\subsubsection{Pharmacist Roles and Expectations Regarding the Management of their Disease}

Patients contact their pharmacist mainly to ask questions about drug therapy rather than about their disease (respectively, $58.0 \%$ and $31.0 \%$ of cases). Reponses are satisfactory or very satisfactory in $77.2 \%$ of cases. But more than $15 \%$ of patients do not have an opinion.

Patients state that contact with their pharmacist is good for any request of information related to treatments (explanation, information on over-the-counter drugs) (Table 4).

However, for disease explanation or medical followup/supervision, attitudes differ. Men think that the pharmacist has a role in medical follow-up and medical supervision, whereas most women do not (respectively, $\mathrm{p}=$ 0.04 and $\mathrm{p}=0.02$ ).

\subsubsection{Therapeutic Education}

$40.6 \%$ of patients indicated that they were familiar with therapeutic education and this was not significantly related to the sex $(p=0.65)$ or age $(p=0.15)$ of patients or to their place of residence (city or country, $\mathrm{p}=0.35$ ). Among patients familiar with therapeutic education, twothirds $(69.2 \%)$ depend on their pharmacist and think that he can. Moreover, $46.2 \%$ of patients had received some form of therapeutic education from their pharmacist.

\section{DISCUSSION}

Heart failure management is a public health priority. The multidisciplinary approach to managing it has been shown to improve outcome, in particular in terms of hospitalisation [4-6,8]. However, the role of the community pharmacist has not been evaluated. Since patients always have to visit their pharmacy to collect their drug therapy, it seems coherent to include community pharmacists in multidisciplinary management. We therefore felt that, by using two questionnaires, we could assess: 1/pharmacists: their knowledge of heart failure and their

Table 3. Grounds of faithfulness.

\begin{tabular}{lc}
\hline Grounds of faithfulness, $\mathrm{n}=88$ & number (\%) \\
\hline $\begin{array}{l}\text { Pharmacist's good drug therapy knowl- } \\
\text { edge }\end{array}$ & $57(64.8)$ \\
$\begin{array}{l}\text { Pharmacist's good advices } \\
\text { Pharmacist's ability to listen to and }\end{array}$ & $33(37.5)$ \\
refer patients to others health profes- & $14(15.5)$ \\
sionals & $69(78.4)$ \\
Proximity of pharmacy & $7(8.0)$ \\
Other & \\
\hline
\end{tabular}

Table 4. Roles attributed to the pharmacist by heart failure patients.

\begin{tabular}{|c|c|}
\hline $\mathrm{n}=96$ & $\begin{array}{l}\text { Is the pharmacist quali- } \\
\text { fied and capable of provi- } \\
\text { ding necessary informa- } \\
\text { tion? number }(\%)\end{array}$ \\
\hline \multicolumn{2}{|c|}{ Disease explanation } \\
\hline Yes & $20(20.8)$ \\
\hline No & $76(79.2)$ \\
\hline \multicolumn{2}{|c|}{ Drug therapy explanation } \\
\hline Yes & $68(70.8)$ \\
\hline No & $28(29.2)$ \\
\hline \multicolumn{2}{|c|}{$\begin{array}{l}\text { Information on over-the } \\
\text {-counter drugs }\end{array}$} \\
\hline Yes & $55(57.3)$ \\
\hline No & $41(42.7)$ \\
\hline \multicolumn{2}{|c|}{ Medical follow-up } \\
\hline Yes & $36(37.5)$ \\
\hline No & $60(62.5)$ \\
\hline \multicolumn{2}{|c|}{ Medical supervision } \\
\hline Yes & $13(13.5)$ \\
\hline No & $83(86.5)$ \\
\hline \multicolumn{2}{|c|}{ Hygieno-dietetic management } \\
\hline Yes & $29(30.2)$ \\
\hline No & $67(69.8)$ \\
\hline \multicolumn{2}{|c|}{$\begin{array}{l}\text { Referral to support } \\
\text { associations }\end{array}$} \\
\hline Yes & $9(9.4)$ \\
\hline No & $87(90.6)$ \\
\hline \multicolumn{2}{|c|}{$\begin{array}{l}\text { Referral to others health } \\
\text { professionals }\end{array}$} \\
\hline Yes & $18(18.8)$ \\
\hline No & $78(81.2)$ \\
\hline
\end{tabular}

roles especially concerning their ability and willingness to provide therapeutic education and 2/patients: roles and expectations regarding pharmacist management of their disease, and also whether or not they trust pharmacists to provide therapeutic education. Pharmacists and patients included in this study constitute a specific sample. Thus, 320 of 437 community pharmacists of the Franche-Comté region $(73 \%)$ received a questionnaire and 118 of them (37\%) responded. Among patients of the Franche-Comté Heart Association, 96 responded. They were not representative of the total number of heart failure patients (selection bias) because they have already accepted the disease and are willing to share their experience with other patients. On the whole, we can consider the patient response rate satisfactory, especially since our study did not include a reminder or anonymous 
follow-up mail to patients.

Heart failure patients, over sixty years old in $88 \%$ of cases (over seventy-five years old in $21 \%$ of cases) are satisfied with their community pharmacist and are faithful to him. They express some expectations related to their questions. To our knowledge, patient expectations have never been studied. For most patients, the community pharmacist is a drug therapy specialist (explanation and information on over-the-counter drugs). However, few patients (between 9\% and 38\%) think that the pharmacist must play other roles such as: disease explanation, medical follow-up, medical supervision, hygieno-dietetics management, referral to support associations or to other health professionals. A better integration and involvement of the community pharmacist in the managing heart failure patients could improve this image. Thus, for example, in terms of public heath, collaboration between support association/health professionals and community pharmacists could be envisaged.

Efforts to promote adherence should be included in programs involving a multidisciplinary team with community pharmacist participation designed to improve heart failure therapy and outcomes. Pharmacists have an important role to play in educating patients. Patient therapeutic education is a vital component of heart failure management and reinforces the importance of medication adherence. Thus, in spite of the fact that $59 \%$ of patients polled did not know about therapeutic education, among those familiar with it, two-thirds depend on their pharmacist and think that he is capable of providing it. Moreover, $46.2 \%$ of patients had received some form of therapeutic education from their pharmacist. $77 \%$ of pharmacists polled know about therapeutic education and they feel that they are able to play this role in $68 \%$ of cases. Therapeutic education ordinarily takes place in a hospital setting. It would be interesting to consider and promote the community pharmacy as an additional setting.

Community pharmacist follow-up more than ten heart failure patients and they tended to return regularly. Indeed, community pharmacists are in a good position to provide a local service. Their work should not be limited to drug dispensation, but must include educating patients about their treatment, informing about the importance of observance and therapeutic education, and providing medical equipment. However, community pharmacists are not comfortable in all fields. Their initial university training about heart failure was considered insufficient or very insufficient by $57 \%$ of community pharmacists. The older the qualifications, the more dissatisfied the pharmacist was with his initial university training. This could explain why pharmacists were unable to answer in $69 \%$ of cases when patients inquired about heart failure. Almost all feel that it is necessary to have continuing education, but only one-third have ever had it. An additional refresher course is essential to remedy this situation and to ensure an effective and competent participation in the multidisciplinary management of heart failure patients.

The design of our study is original, exploring both the pharmacist and the patient's point of view. It is debatable whether or not the present study results may be compared with those obtained in the literature. Some studies have assessed the role of the community pharmacist in the management of heart failure [9-13]. Thus, Gattis et al. show that heart failure outcomes can be improved with a clinical pharmacist as an important component of the multidisciplinary heart failure team [14]. Pharmacists contribute to the overall care of these patients, but should be appropriately trained. Murray et al. show that pharmacist intervention for outpatients with heart failure can improve adherence to cardiovascular medications and decrease health care use and costs, but the benefit probably requires constant involvement because the effect dissipates when the intervention ceases [13]. Pharmacist received training for their intervention. The same is true of the Bouvy et al. study [9].

In the United Kingdom, the government has been encouraging an extension to the role of community pharmacists, including independent prescribing, medicine use review and a health promotion role to provide advice about, diet and nicotine addiction, among other issues [15]. In the United Arab Emirates, the introduction of a clinical pharmacy programme involving optimization of drug treatment and intensive education and self-monitoring of patients [11]. In Canada, the involvement of pharmacists in problems of patient compliance goes back many years and has been studied through the PRECEDE pharmacist education program which espouses a thorough structured approach to patient education incorporating patient's beliefs [16]. Community-based pharmacists are embedded in an infrastructure where they are essential for patients to receive medication.

Pharmacist's involvement in a disease management program will improve the care given to patients with heart failure.

\section{CONCLUSIONS}

In spite of biases, this study allows us to assess the expectations of heart failure patients with regard to the pharmaceutical management of their disease, thus, clarifying the indispensable contribution that pharmacists make in managing this disease.

\section{ACKNOWLEDGEMENTS}

We would like to thank all patients of the Franche-Comte Heart Asso- 
ciation and the community pharmacists who contributed to this study. We also thank Ms Pamela Albert for proofreading the manuscript.

\section{CONFLICTS OF INTEREST}

There is no potential conflict of interest related to the content of this manuscript.

\section{REFERENCES}

[1] Arnold, J.M., Liu, P., Demers, C., Dorian, P., Giannetti, N., Haddad, H., Heckman, G.A., Howlett, J.G., Igaszewski, A., Johnstone, D.E., Jong, P., McKelvie, R.S., Moe, G.W., Parker, J.D., Rao, V., Ross, H.J., Sequeira, E.J., Svendsen, A.M., Teo, K., Tsuyuki, R.T. and White, M. (2006) Canadian cardiovascular society consensus conference recommendations on heart failure 2006: Diagnosis and management. The Canadian Journal of Cardiology, 22(1), 23-45.

[2] Delahayeand F. and de Gevigney, G. (2001) Epidémiologie de l'insuffisance cardiaque. Annales de Cardiologie et d'Angéiologie, 50(1), 6-11.

[3] Vinson, J.M., Rich, M.W., Sperry, J.C., Shah A.S. and McNamara, T. (1990) Early readmission of elderly patients with congestive heart failure. Journal of the American Geriatrics Society, 38(12), 1290-1295.

[4] Racine-Morel, A., Deroche, S., Bonnin, C., Gérard C. and Matagrin, C. (2006) Prise encharge dupatient insuffisant cardiaque: Évolution, organisation, application àl'échelle locale. Annales de Cardiologie et d'Angéiologie, 55(6), 352-357.

[5] Rich, M.W., Beckham, V., Wittenberg, C., Leven, C.L., Freedland K.E. and Carney, R.M. (1995) A multidisciplinary intervention to prevent the readmission of elderly patients with congestive heart failure. The New England journal of Medicine, 233(18), 1190-1195.

[6] Koelling, T.M., Johnson, M.L., Cody R.J. and Aaronson K.D. (2005) Discharge education improves clinical outcomes in patients with chronic heart failure. Circulation, 111(2), 179-185.

[7] Gwadry-Sridhar, F., Guyatt, G., O'Brien, B., Arnold, J.M., Walter, S., Vingilis, E. and MacKeigan, L. (2008) TEACH: Trial of education and compliance in heart dysfunction chronic disease and heart failure (HF) as an increasing problem. Contemporary Clinical Trials, 29(6), 905-918.

[8] Omar, A.R., Suppiah, N., Chai, P., Chan, Y.H., Seow, Y.
H., Quek, L.L., Poh, K.K. and Tan, H.C. (2007) Efficacy of community-based multidisciplinary disease management of chronic heart failure. Singapore Medical Journal, 48(6), 528-531.

[9] Bouvy, M.L., Heerdink, E.R., Urquhart, J., Grobbee, D.E., Hoes A.W. and Leufkens, H.G. (2003) Effect of a pharmacist-led intervention on diuretic compliance in heart failure patients: A randomized controlled study. Journal of Cardiac Failure, 9(5), 404-411.

[10] Holland, R., Brooksby, I., Lenaghan, E., Ashton, K., Hay, L., Smith, R., Shepstone, L., Lipp, A., Daly, C., Howe, A., Halland R. and Harvey, I. (2007) Effectiveness of visits from community pharmacists for patients with heart failure: HeartMed randomised controlled trial. British Medical Journal, 334(7603), 1098-1101.

[11] Sadik, A., Yousifand, M. and McElnay, J.C. (2005) Pharmaceutical care of patients with heart failure. British Journal of Clinical Pharmacology, 60(2), 183-193.

[12] Murray, M.D., Young, J.M., Morrow, D.G., Weiner, M., Tu, W., Hoke, S.C., Clark, D.O., Stroupe, K.T., Wu, J., Deer, M.M., Bruner-England, T.E., Sowinski, K.M., Smith, F.E., Oldridge, N.B., Gradus-Pizlo, I., Murray, L.L., Brater D.C. and Weinberger, M. (2004) Methodology of an ongoing, randomized, controlled trial to improve drug use for elderly patients with chronic heart failure. The American Journal of Geriatric Pharmacotherapy, 1(1), 53-65.

[13] Murray, M.D. Young, J., Hoke, S., Tu, W., Weiner, M., Morrow, D.D., Stroupe, K.T., Wu, J., Clarke, D., Smith, F., Gradus-Pizlo, I., Weinberger, M. and Brater, D.C. (2007) Pharmacist intervention to improve medication adherence in heart failure: A randomized trial. Annals of Internal Medicine, 146(10), 714-725.

[14] Gattis, W.A., Hasselblad, V., Whellanand, D.J. and $\mathrm{O}^{\prime}$ Connor, C.M. (1999) Reduction in heart failure events by the addition of a clinical pharmacist to the heart failure management team: Results of the pharmacist in heart failure assessment recommendation and monitoring (PHARM) study. Archives of Internal Medicine, 159(16), 1939-1945.

[15] Department of Health (2005) Choosing health through pharmacy - A programme for pharmaceutical public health 2005-2015. Department of Health, London.

[16] Bucci, C. Jackevicius, C., McFarlane K. and Liu, P. (2003) Pharmacist's contribution in a heart function clinic: Patient perception and medication appropriateness. The Canadian Journal of Cardiology, 19(4), 391-396. 